\title{
A fourteen-year audit of surgery for inflammatory bowel disease at a tertiary colorectal unit
}

\author{
SM Chonco, ${ }^{1}$ (i) PN Mtetwa, ${ }^{1}$ (i) M Naidoo, ${ }^{1}$ (i) VG Naidoo, ${ }^{2}$ (i) TE Madiba ${ }^{1}$ (i) \\ ${ }^{1}$ Department of Surgery, University of KwaZulu-Natal, South Africa \\ ${ }^{2}$ Department of Gastroenterology, University of KwaZulu-Natal, South Africa
}

Corresponding author, email: maseelan@gmail.com

Background: In South Africa, inflammatory bowel disease (IBD) is increasing in frequency. The purpose of the study was to document our experience with the surgical management of patients with IBD and describe the cohort undergoing surgical management of IBD in a KwaZulu-Natal province tertiary state sector hospital.

Methods: Retrospective analysis of a database of patients undergoing surgery for IBD. Demographics, site and disease duration, surgical indications, management and outcome were analysed.

Results: Of 397 patients with IBD, 136 had Crohn's disease (CD) (African 13, Indian 78, Coloured 10 and White 35) and 261 had ulcerative colitis (UC) (African 67, Indian 158, Coloured 9 and White 27). Eighty-six of 136 patients with $\mathrm{CD}$ required surgical referral. Ileo-colonic $\mathrm{CD}$ was most common and non-stricturing/non-penetrating disease behaviour predominated. Seventy-four patients with CD underwent 76 abdominal surgical procedures with in-hospital mortality of $3.5 \%$ and a morbidity of $20.9 \%$. Twenty patients required anorectal fistula procedures. Recurrence occurred in nine patients $(10.5 \%)$ and malignant transformation was seen in three patients $(2.2 \%)$. One hundred and sixty-three of the 261 patients with UC had pancolitis. Failed medical management was the most common indication for surgical referral. Fiftyone patients with UC had surgery, (age 44.5 [IQR 27-56] years). Forty-five patients underwent 63 abdominal surgical procedures with an overall mortality of $17.7 \%$ and a morbidity of $39.2 \%$. Colorectal cancer was seen in 10 patients (3.8\%). Laparoscopic procedures were undertaken in eight CD patients $(10.8 \%)$ and 29 UC patients $(39 \%)$. The median hospital stay was 7 days for both open and laparoscopic resection.

Conclusion: IBD is not uncommon in African patients, with UC being more frequent than CD. Postoperative mortality and potential for malignant transformation are higher for UC.

Keywords: inflammatory bowel disease, Crohn's disease, ulcerative colitis, surgical management

\section{Introduction}

Inflammatory bowel disease (IBD) represents a group of idiopathic chronic inflammatory intestinal conditions, the two main disease categories being Crohn's disease (CD) and ulcerative colitis (UC). ${ }^{1} \mathrm{CD}$ is transmural, affecting all segments of the gastrointestinal tract. ${ }^{2} \mathrm{UC}$ is confined to the colonic mucosa only, almost always involving the rectum with variable continuous proximal extension. ${ }^{3}$

The global annual incidence of IBD is 5.0-24.3 per 100000 person-years. ${ }^{4}$ However, its prevalence varies globally ${ }^{5}$ and studies from various countries demonstrate an increasing incidence. ${ }^{4,6}$ Historically, the highest prevalence rates have been reported in White populations, particularly those of North America and Europe, with significantly lower rates seen in Black and Asian populations within these countries. ${ }^{1,5,6}$ IBD generally begins in young adulthood and lasts throughout life. ${ }^{4,7}$ Its course is characterised by episodic remissions and relapses with distinct yet overlapping clinical and pathological features. ${ }^{8}$

Due to the fact that the majority of reports on this disease originate primarily from populations in high-income countries (HICs), there is a paucity of literature in sub-
Saharan Africa and other low- to middle-income countries (LMICs). ${ }^{4}$ In South Africa, IBD is a well-recognised entity in the White population but is relatively rare in the indigenous African populations. ${ }^{1}$ This rarity among African populations is seen in the rest of Africa. ${ }^{9}$

The management of patients with IBD requires a multidisciplinary team (MDT) approach. ${ }^{10}$ Medical therapy is the mainstay of treatment and is directed at control of the underlying inflammatory process and improvement of symptoms. ${ }^{10}$ Despite the advances in medical therapy, up to $45 \%$ of patients with $\mathrm{UC}^{3,10-12}$ and up to $61 \%$ of patients with $\mathrm{CD}$ will require surgical intervention at some point., ,, $13^{13}$

A few studies from sub-Saharan Africa have reported on IBD $^{1,14-16}$ and one has addressed the risk of colectomy in UC. ${ }^{17}$ However, no studies have described the surgical aspects of IBD management in detail. In an attempt to address this dearth of data in the South African context, we undertook this observational case study in a tertiary colorectal unit in Durban. We proposed that the surgical indications in our setting are similar to those seen worldwide and we sought to document our experience with the surgical management of 
patients with IBD. We used an existing database of patients with IBD disease requiring surgical intervention.

\section{Methods}

This was a retrospective observational case study of patients with IBD from KwaZulu-Natal referred for surgical intervention over a 14-year period (2005-2018). The study was conducted in the Colorectal Unit at Inkosi Albert Luthuli Central Hospital (IALCH), a tertiary teaching centre in Durban, South Africa, which is the only quaternary hospital serving the province of KwaZulu-Natal. Patients with IBD at IALCH are managed by an MDT led by medical gastroenterologists and colorectal surgeons.

Patient data were extracted from a prospectively collected IBD database into which patients referred for surgical intervention were entered. This database is archived by the Gastrointestinal Cancer Research Group of the Department of Surgery at the University of KwaZulu-Natal. Patients with $\mathrm{CD}$ and UC were included in the analysis whilst patients with "indeterminate colitis" and other colitides were excluded. Population groups are defined as African, Indian, Coloured and White according to the criteria used by the South African Government. ${ }^{18}$ In South Africa, "Coloured" refers to people of mixed ancestry. ${ }^{18}$ Data collected and analysed included demographics, clinical presentation, extent of disease, duration before referral, surgical indications, management and outcome. The study outcome measures were hospital stay, in-hospital mortality and morbidity, as well as long-term follow-up. Disease distribution and behaviour were reported using the Montreal Classification of IBD. ${ }^{19}$ Data were entered onto a clinical proforma and subsequently analysed using Microsoft Excel. Early complications were defined as complications occurring on the same admission or within 30 days of surgery. Complications occurring after discharge were regarded as late complications. Short-term follow-up was undertaken in the colorectal clinic and the long-term follow-up was undertaken at the medical gastroenterology clinic, both at IALCH. CD-related anorectal fistulae are generally managed conservatively and incidental anorectal fistula disease in UC patients was managed on its merits.

\section{Results}

Figure 1 shows sample derivation of patients with IBD. Four hundred and nine consecutive IBD patients were managed by the combined team at IALCH: 136 with CD and 261 with UC. Eighty-six of 136 of CD patients and 51 of 261 of UC patients were referred to surgery. The rest of the patients were successfully managed medically. Table I shows the profile of patients referred to surgery. Median age at diagnosis of CD was 29 years (IQR 24-38) and median age at referral to surgery was 32 years (IQR 26-41). The median duration of disease before referral to surgery was 35 months (IQR 3-111).

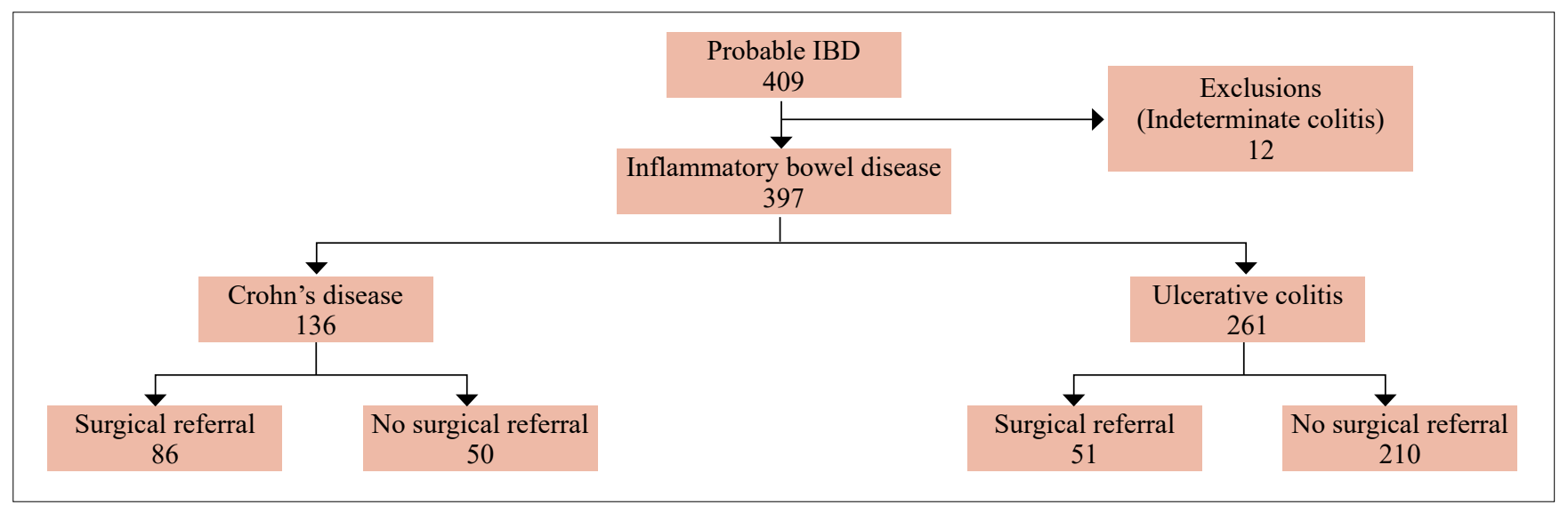

Figure 1

Table I: Profiles of all IBD patients

\begin{tabular}{|c|c|c|c|c|}
\hline \multirow{2}{*}{ Parameter } & \multicolumn{4}{|c|}{ IBD type } \\
\hline & \multicolumn{2}{|c|}{ CD } & \multicolumn{2}{|c|}{ UC } \\
\hline Overall & \multicolumn{2}{|c|}{136} & \multicolumn{2}{|c|}{261} \\
\hline Males & \multicolumn{2}{|c|}{52} & \multicolumn{2}{|c|}{126} \\
\hline \multirow[t]{2}{*}{$\mathrm{M}: \mathrm{F}$ ratio } & \multicolumn{2}{|c|}{$1: 1.6$} & \multicolumn{2}{|c|}{$1: 1.1$} \\
\hline & $n$ & IQR & $n$ & IQR \\
\hline Age at diagnosis (years): $n$ (IQR) & 29 & $24-38$ & 35 & $21-50$ \\
\hline Age at referral to surgery: $n$ (IQR) & 32 & $26-41$ & 44 & $26-56$ \\
\hline \multirow[t]{2}{*}{ Duration of disease before referral (months) } & 35 & $3-111$ & 30.5 & $6-109$ \\
\hline & $n$ & $\%$ & $n$ & $\%$ \\
\hline African & 13 & 9.6 & 67 & 25.7 \\
\hline Indian & 78 & 57.4 & 158 & 60.5 \\
\hline Coloured & 10 & 7.4 & 9 & 3.5 \\
\hline White & 35 & 25.7 & 27 & 10.4 \\
\hline
\end{tabular}


Table II: Disease characteristics at diagnosis

\begin{tabular}{lcc}
\hline Crohn's disease $(\boldsymbol{n}=\mathbf{1 3 6})$ & & \\
\hline Montreal classification for disease extent & $\boldsymbol{n}$ & $\boldsymbol{\%}$ \\
\hline L1: Ileal & 1 & 0.7 \\
LE: Colonic & 35 & 25.7 \\
L3: Ileo-colonic & 100 & 73.5 \\
Montreal classification for disease behaviour & & \\
\hline B1: Non-stricturing/non-penetrating & 84 & 61.8 \\
B2: Stricturing & $43^{*}$ & 31.6 \\
B3: Penetrating & $11^{*}$ & 8 \\
p: Anorectal disease & 20 & 14.7 \\
Upper GI & 0 & 0 \\
Extra-intestinal manifestations (EIMs) & 23 & 16.9 \\
Ulcerative colitis $(\boldsymbol{n}=\mathbf{2 6 1})$ & & \\
\hline Montreal classification for disease location & & \\
\hline E1: Ulcerative proctitis & 0 & 0 \\
E2: Left-sided colitis & 98 & 37.6 \\
E3: Pancolitis & 163 & 62.5 \\
EIMs & 42 & 16.1 \\
\hline
\end{tabular}

* Three patients had coexistent structuring and penetrating disease

Table III: Indications for surgical intervention in patients with inflammatory bowel disease

\begin{tabular}{|c|c|c|c|c|}
\hline \multirow{2}{*}{ Indications } & \multicolumn{2}{|l|}{ CD } & \multicolumn{2}{|c|}{$\mathbf{U C}$} \\
\hline & $n$ & $\%$ & $n$ & $\%$ \\
\hline Total & 86 & & 51 & \\
\hline $\begin{array}{l}\text { Stricture leading to obstructive } \\
\text { symptoms }\end{array}$ & 44 & 51.2 & 5 & 9.8 \\
\hline Anorectal disease & 20 & $23.2^{\mathrm{a}}$ & 17 & $33^{\mathrm{b}}$ \\
\hline Enteric fistula ${ }^{c}$ & 13 & 15.1 & - & - \\
\hline Inflammatory mass & 9 & 10.5 & 1 & 1.9 \\
\hline Perforation $^{\mathrm{d}}$ & 6 & 10.5 & - & - \\
\hline Acute severe colitis & 8 & 9.3 & 16 & 31.4 \\
\hline Failure of medical management & 9 & 10.5 & 20 & 39.2 \\
\hline Benign anorectal stricture & 1 & 1.2 & - & - \\
\hline Uncontrollable bleeding & - & - & 1 & 1.9 \\
\hline Cancer & 2 & 2.3 & 7 & 13.7 \\
\hline Villous adenoma & - & - & 1 & 2 \\
\hline Primary sclerosing cholangitis & - & - & 2 & 3.9 \\
\hline Hilar cholangiocarcinoma & - & - & 1 & 2 \\
\hline \multicolumn{5}{|c|}{ 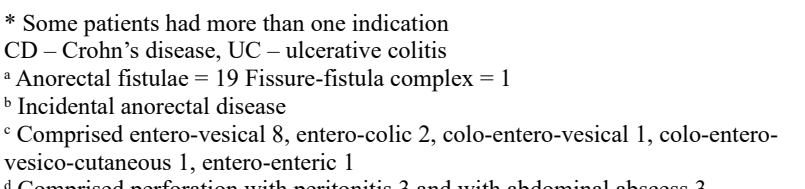 } \\
\hline
\end{tabular}

As can be seen in Table II, the most common site for CD was ileo-colonic. Extra-intestinal manifestations (EIMs) were seen in 23 patients $(17 \%)$. The $20 \mathrm{CD}$ patients with anorectal fistula disease included 19 cryptoglandular fistulae and one fissure-fistula complex. Indications for surgery are shown in Table III. The most common indication for surgical
Table IV: Surgical procedures undertaken in patients with Crohn's disease

\begin{tabular}{ll}
\hline Procedure & $\boldsymbol{n}$ \\
\hline Right hemicolectomy & 57 \\
Procedures for anorectal fistula disease & 20 \\
$\quad$ Insertion of seton & 15 \\
$\quad$ Fistulotomy of fissure-fistula followed by & 1 \\
$\quad$ conservative management & 1 \\
$\quad$ I+D perianal abscess followed seton insertion & 3 \\
$\quad$ Conservative & 1 \\
Procedure for idiopathic anorectal stricture & 1 \\
$\quad$ Multiple anal dilatations followed by APR & 5 \\
Total colectomy + ileostomy & 2 \\
Right hemicolectomy + sigmoidectomy & 2 \\
Left hemicolectomy & 1 \\
Right hemicolectomy followed by total colectomy & 1 \\
Ileal resection & 1 \\
Transverse colectomy & 1 \\
Sigmoid colectomy & 2 \\
Total colectomy + ileostomy & \\
Laparotomy + adhesiolysis & 1 \\
No abdominal surgery (refused) & 1 \\
* Some patients had more than one procedure \\
a Includes 3 extended right hemicolectomies \\
' Ileostomy subsequently converted to ileo-rectal anastomosis & 1
\end{tabular}

Table V: Surgical procedures undertaken in patients with ulcerative colitis

\begin{tabular}{lc}
\hline First procedure & $\boldsymbol{n}$ \\
\hline Anterior resection $^{\mathrm{a}}$ & 1 \\
Non-operative $^{\mathrm{a}}$ & 6 \\
Proctocolectomy + ileostomy $_{\text {Proctocolectomy + IPAA }}$ & 2 \\
Total colectomy + ileostomy & 11 \\
Total colectomy + IRA & 23 \\
Trial of dissection no resection & 2 \\
Right hepatectomy + hepaticojejunostomy & 1 \\
Laparotomy for primary peritonitis & 1 \\
Liver transplant & 1 \\
\hline
\end{tabular}

IPAA - ileal pouch-anal anastomosis, IRA - ileo-rectal anastomosis

${ }^{a}$ Six patients did not undergo abdominal surgery

${ }^{\mathrm{b}}$ Underwent 15 secondary procedures namely completion procedures (14) and abdominoperineal resection (1). Some patients did not have a completion procedure

referral was bowel stricture with obstructive symptoms. Seventy-four of 86 patients $(86 \%)$ underwent 76 abdominal surgical procedures (Table IV). The most common resectional procedure was a right hemicolectomy. Nineteen patients required emergency abdominal surgery (26.3\%). One patient with benign anorectal stenosis was managed by repeated anal dilatations, but eventually required abdominoperineal resection (APR) for refractory stricture. One patient referred for failed medical management declined surgery and was managed conservatively. He improved on conservative management and was sent back to the base hospital in a stable condition. Anorectal fistula disease was 
Table VI: Surgical complications in patients undergoing abdominal procedures for IBD

\begin{tabular}{|c|c|c|c|}
\hline $\begin{array}{l}\text { Clavien-Dindo } \\
\text { classification }\end{array}$ & Complication & $\begin{array}{c}\text { Crohn's disease } \\
n=86\end{array}$ & $\begin{array}{c}\text { Ulcerative colitis } \\
\qquad n=51\end{array}$ \\
\hline Total & Patients with complications & $17(19.8 \%)$ & $21(41.2 \%)$ \\
\hline \multirow[t]{4}{*}{ Grade I } & Surgical site infection & 0 & 4 \\
\hline & Prolonged ileus & 0 & 1 \\
\hline & Thalamic infarct & 0 & 2 \\
\hline & Sub-total & 0 & $5(9.8 \%)$ \\
\hline \multirow[t]{2}{*}{ Grade II } & Acidosis & 0 & 0 \\
\hline & Sub-total & 0 & 0 \\
\hline \multirow[t]{9}{*}{ Grade III } & Peritonitis & 6 & 2 \\
\hline & Haemorrhage & 0 & 1 \\
\hline & SSI & 4 & 1 \\
\hline & POI & 3 & 0 \\
\hline & Bladder injury & 1 & 0 \\
\hline & Enterocutaneous fistula & 8 & 1 \\
\hline & Abd abscess & 6 & 2 \\
\hline & Anastomotic leak & 5 & 2 \\
\hline & Sub-total & $14(16.3 \%)$ & $5(9.8 \%)$ \\
\hline \multirow[t]{8}{*}{ Grade IV } & MODS & 1 & 1 \\
\hline & Peritonitis & 0 & 0 \\
\hline & SS1 & 0 & 1 \\
\hline & Abd abscess & 1 & 0 \\
\hline & Renal dysfunction & 0 & 1 \\
\hline & Intestinal obstruction & 0 & 1 \\
\hline & POI & 0 & 1 \\
\hline & Sub-total & $1(1.2 \%)$ & $2(3.9 \%)$ \\
\hline \multirow[t]{12}{*}{ Grade V } & Renal dysfunction & 0 & 1 \\
\hline & MODS & 0 & 6 \\
\hline & Peritonitis & 1 & 3 \\
\hline & SSI & 0 & 2 \\
\hline & Fistula & 0 & 1 \\
\hline & POI & 0 & 3 \\
\hline & Stump blow-out & 0 & 1 \\
\hline & UTI & 0 & 1 \\
\hline & Cerebellar infarct & 0 & 1 \\
\hline & Anastomotic leak & 2 & 2 \\
\hline & DVT + IVC thrombosis & 0 & 1 \\
\hline & Sub-total & $2(2.3 \%)$ & $9(17.7 \%)$ \\
\hline
\end{tabular}

The subtotal and total are the numbers of patients with the complications and not the number of complications.

* Some patients developed more than one complication.

SSI - surgical site infection, MODS - multi-organ dysfunction syndrome, UTI - urinary tract infection, POI - postoperative ileus, DVT - deep vein thrombosis, IVC -

inferior vena cava

managed by seton placement. As shown in Table VI, early postoperative complications occurred in 17 patients (19.8\%), all of whom required re-look laparotomies. Six patients died, giving an overall mortality rate of $4.4 \%$, two of whom died in the postoperative period (in-hospital mortality rate $3.5 \%$ ). Three patients $(2.2 \%)$ had gastrointestinal cancer, namely colorectal cancer diagnosed preoperatively (2), and small bowel adenocarcinoma diagnosed at surgery.

Median follow-up after surgery was 33.5 (IQR 1-76) months. Recurrent disease occurred in nine patients $(10.5 \%)$ and manifested as ileal stricture (3), duodenal stricture (2), enteric fistula (2), pelvic abscess (1) and inflammatory mass (1). The two enteric fistulae were colo-vesical and colo-cutaneous. One patient with colo-vesical fistula and pelvic collection went on to develop sepsis and multi-organ dysfunction syndrome (MODS) and died before surgery could be undertaken. She survived 121 months after the original surgery.

The 51 patients with UC referred for surgical intervention had a median age of 44.5 (IQR 27-56) years at the time of surgical referral. The median duration of disease before surgical referral was 30.5 (IQR 6-109.5) months. As shown 
in Table II, the majority of patients had pancolitis (E2). Forty-two patients $(27 \%)$ had EIM of the disease.

The common indications for surgery were failed medical therapy and acute severe colitis (Table III). Table V shows procedures undertaken. Forty-five patients underwent 63 abdominal procedures. The most commonly performed elective procedure was proctocolectomy \& ileal pouch anal anastomosis (IPAA) and the most commonly performed emergency procedure was total colectomy \& ileostomy. Of the 23 patients undergoing emergency total colectomy and ileostomy, 14 went on to have completion proctectomy and IPAA and one had APR; the rest remained with an ileostomy. The two patients with primary sclerosing cholangitis underwent transplantation and one patient with hilar cholangiocarcinoma underwent right hepatectomy and hepaticojejunostomy. One patient required two exploratory laparotomies, the initial one for primary peritonitis and the subsequent one for bleeding. Six patients were managed nonoperatively for various reasons including refusal of surgery (3), default prior to surgery (1) death prior to surgery (1) and palliative stent insertion for malignant lesion due to poor general condition (1). Twelve of the patients undergoing abdominal surgery required emergency surgery. Seventeen patients with incidental anorectal fistulae were managed by seton placement.

Ten patients $(3.8 \%)$ were found to have colon cancer at a median age of 43 years. Diagnosis of cancer was made preoperatively in seven patients and postoperatively in three patients. Of the latter three patients, all had undergone colonoscopy in the preceding year. Two had had a normal colonoscopy in the preceding year and the last patient was diagnosed with the primary disease three months previously and the indication for surgical referral was an "inflammatory mass", which turned out to be cancer. The sites involved with cancer were rectum (4), sigmoid colon (3), transverse colon (2) and caecum (1).

Postoperative complications for both $\mathrm{CD}$ and $\mathrm{UC}$, stratified according to the Clavien-Dindo classification, are shown in Table VI. The postoperative complication rate was $19.8 \%$ for CD and $41.2 \%$ for UC. Grade III complications were the most commonly seen in $\mathrm{CD}$, whereas grade $\mathrm{V}$ were the most commonly seen in UC. Six patients with CD died (7\%), two of whom died within 30 days of the abdominal procedure (making a 30-day mortality rate of 3.5\%) and the rest died during follow-up. Nine patients with UC died (overall mortality $17.7 \%$ and $20 \%$ mortality following abdominal surgery). Five patients died in hospital during initial admission; one of these died without operation as she was too sick to undergo surgery. The remaining four patients who died had been readmitted for a complication and died in hospital because of postoperative complications. The patients with anorectal disease are still being followed up as are the three patients managed conservatively for colonic disease.

Eight of the 76 abdominal procedures $(10.8 \%)$ for $\mathrm{CD}$ and 31 of the 63 abdominal procedures for UC (46\%) were scheduled for laparoscopy. There were no conversions among CD patients and two conversions among UC patients, allowing complete laparoscopy in 29 patients. All laparoscopic procedures were performed by one surgeon (NM). Late complications occurred in one CD patient (1\%) who developed intestinal obstruction, requiring laparotomy and adhesiolysis. Eight UC patients (16\%) developed late complications; four had intestinal obstruction which was managed with adhesiolysis (2) and bowel resection (2), one patient developed pouch dysfunction which required eventual removal, one had pouchitis which was managed non-operatively with antibiotics and one patient had a parastomal hernia which needed repair. Median hospital stay for CD and UC was 7 days (IQR 5-39) and 7 days (IQR 6-13) respectively. Three patients required critical care admission with median ICU stay of 3 days. The hospital stay for both laparoscopic and open procedures was 7 days. Median follow-up was 59 (IQR 21.5-118) months for CD and 56.5 (IQR 25.5-98) months for UC.

\section{Discussion}

Although the findings in this study share some similarities with the current international literature, there are some significant contrasting observations. IBD was observed in all population groups, and this is in keeping with findings from a previous South African study. ${ }^{1}$ According to the midyear population estimates, the South African population is 57730000 with KwaZulu-Natal province, comprising $20 \%$ of the population of whom $85 \%, 8.5 \%, 5 \%$ and $1.5 \%$ are African, Indian, White, and Coloured respectively. The study showed that Indians and Whites, who comprise $8.5 \%$ and $5 \%$ of the population respectively, constituted $59 \%$ and $22 \%$ of patients with IBD respectively. This demonstrates a greater relative proportion of affected Indian and White patients relative to their demographic representation in the entire province. The fact that Africans contributed $12 \%$ and $18 \%$ to the disease burden of CD and UC respectively contrasts the previously held view that IBD is rare in Africans patients, ${ }^{1,9}$ and supports the growing evidence that this disease is increasingly being seen in all sub-Saharan African population groups as reported in countries like Uganda, Nigeria and South Africa. ${ }^{1,9}$

EIMs are seen in $25-40 \%$ of patients with IBD. ${ }^{20}$ The EIMs were seen in $17 \%$ of $\mathrm{CD}$ patients in this series compared to the $40 \%$ reported in the literature ${ }^{20}$ and in $16 \%$ of UC patients, which is higher than the $4.5-8 \%$ seen in certain Asian studies, ${ }^{21}$ but lower than the $30-45 \%$ reported in the Western literature. ${ }^{1,21,22}$ We concede that this is a select group of patients and this observation cannot be generalised to all patients with IBD.

We demonstrated a slight female predominance of IBD in our population, and this predominance was seen in both CD and UC. These data are contrary to other recent studies, which support a female predominance in $\mathrm{CD}$ and either no difference or a male predominance in UC. ${ }^{23}$ The median age of 29 years at diagnosis and 32 years at referral to surgery for CD compares well with the 26-45 years reported in the literature. ${ }^{24}$ The median age at diagnosis of UC and time of referral for surgery was 35 years and 44 years respectively. International literature reports a delay of 5-9 years before surgical referral..$^{25,26}$ The median duration of disease between diagnosis and surgical referral was 36 and 39.5 years respectively for $\mathrm{CD}$ and $\mathrm{UC}$ in this series and suggests an earlier development of complications of IBD compared to international literature. Although the literature suggests an increasing trend in the prevalence of IBD with each decade of life, ${ }^{23}$ we were not able to demonstrate this as it was not the focus of our study.

The cumulative probability of surgery in patients with $\mathrm{CD}$ increases over time with reported rates varying between 
44-71\%. ${ }^{13,27}$ The $63 \%$ seen in this series falls within this figure. Stricturing disease leading to obstruction seen in $31.6 \%$ in this series falls within the reported $20-35 \% .^{7,24}$ The $19 \%$ enteric fistula rate was similar to the reported $8-24 \% .{ }^{24}$ Most notably, failure of medical management was very uncommon at $10.5 \%$, falling below the reported rate of $14-47 \% .{ }^{24}$ Enteric fistulae is a complex manifestation of CD seen in $17-50 \%$ of patients with CD. ${ }^{28}$ Its management requires close multidisciplinary teamwork, and surgery should be delayed until the condition has been optimised. ${ }^{28}$

Surgery requires resection of the affected abdominal wall, the fistula tract and the affected bowel segment with the anastomosis separated from the abdominal wall with omentum, if possible. ${ }^{28}$ Bowel resection is a common intervention in $\mathrm{CD}$, undertaken in $57-97.5 \%,{ }^{24,27}$ which compares well to the $86 \%$ seen in this series. We did not perform strictureplasty in this series despite the fact that it is chosen as an option in $1-18 \%$ of patients with stricturing small bowel CD in the world literature. ${ }^{2}$

The risk of perineal manifestation in $\mathrm{CD}$ increases with disease duration and is reported in $25-30 \%$ of patients. ${ }^{2,24,29}$ It was slightly lower in this series at $22 \%$. We routinely use drainage (non-cutting) setons in our unit for patients with IBD-related anorectal fistulae. Biologicals would be an important component in the treatment strategy for Crohn's perianal fistula supported by surgery; ${ }^{30}$ however, access to biologicals is restricted in our setting due to cost concerns.

The postoperative complication rate was $20 \%$. The $3.5 \%$ postoperative mortality rate following laparotomy fell within the $2.9-18.6 \%$ reported in the literature. ${ }^{24} \mathrm{~A}$ recurrence rate of $21 \%$ was seen in this series. Postoperative recurrence rates increase with the duration of disease after surgery, the recurrence rate being $17-55 \%$ at 5 years, $32-76 \%$ at 10 years and $72-73 \%$ at 20 years. ${ }^{31}$ In patients with Crohn's disease, cancer of small and large bowel is seen in $1.9 \% .{ }^{32}$ It was seen in $2.2 \%$ in this series. The risk of small-bowel adenocarcinoma is 20-30 times that in patients without Crohn's disease ${ }^{33}$ and is reported at $1.7 \%$ in the literature. ${ }^{32}$

The proportion of patients with UC requiring surgical referral was $19.5 \%$, which falls within the $15-30 \%$ reported in the literature. ${ }^{10}$ An overwhelming majority of the patients with UC presented with pancolitis in this series.

The literature, however, shows no consistency of disease extent in the literature, with pancolitis reported to occur in $20-77 \%$ of patients in the general UC population, ${ }^{11,21,22}$ followed by left-sided colitis at $17-20 \%$ and proctitis in $3-4.5 \%$. $^{1,11}$

Indications for surgery include cancer risk, intractability, acute severe colitis, fulminant colitis and perforation. ${ }^{11,21}$ Failed medical therapy is the most common indication for surgical referral at $44 \%,{ }^{21}$ an observation made in this series with failed medical therapy being an indication in $39 \%$ of cases. Acute severe colitis was the next most common indication at $31 \%$, which is a little higher than the reported $5-15 \% .{ }^{17}$ Proctocolectomy and IPAA is the surgery of choice for UC because it removes the diseased colon and maintains gut continuity. ${ }^{10}$ In emergency settings, a total colectomy and ileostomy is the recommended procedure..$^{10,11}$ It is not surprising that total colectomy and ileostomy were the most commonly performed emergency procedures and proctocolectomy and IPAA was the most common elective procedure.
The postoperative complication rate was $41 \%$. The postoperative mortality of $17.7 \%$ is higher than the reported $0.6-13.6 \%$ reported in the literature. ${ }^{11}$ Postoperative deaths and complications in LMICs are potentially preventable and mortality and morbidity rates can be improved by improved systems-wide monitoring and evaluation of surgical care overall, use of surgical safety checklists and improved access to healthcare. ${ }^{34} \mathrm{We}$ urge our policymakers to facilitate the establishment of these proposed protocols in our health facilities in order to improve healthcare access and reduce mortality and morbidity.

Late pouch-related complications following proctocolectomy and IPAA include pouchitis (in about a third of patients), pouch-vaginal fistula, and later pouch dysfunction due to pouch sepsis and pouchitis. ${ }^{11,22,25}$ Late complications were present in $16 \%$ of the patients in this series. Three per cent of our patients with UC developed colorectal cancer, which falls within the $2-27 \%$ reported in international studies. ${ }^{3,10,11}$ The severity of complications varied between the two conditions. Although CD displayed aggressiveness in behaviour, requiring more surgical procedures, it was associated with fewer grade V Clavien-Dindo complications when compared to UC.

Our laparoscopy rate of $10.8 \%$ for CD and $46 \%$ for UC demonstrates the increasing employment of laparoscopy in our colorectal unit. Even though this was not a comparison study, the hospital stay in our study was similar among both laparoscopic and open procedures and the conversion rate was very low. Studies have demonstrated a shorter or similar hospital stay for patients undergoing laparoscopic surgery compared to open surgery for UC. ${ }^{35}$

The study does have some limitations. It was a retrospective analysis. The numbers are relatively small and thus may have led to bias. Despite these limitations, the study does provide an understanding of the clinicopathological status of IBD in the KwaZulu-Natal province of South Africa.

\section{Conclusion}

IBD is not uncommon in African patients, with UC being more frequent than $\mathrm{CD}$. Postoperative mortality and potential for malignant transformation are higher for UC. Surgical resection appears to be the preferable management of IBD complications with minimal in-hospital mortality.

\section{Conflict of interest}

The authors declare no conflict of interest.

\section{Funding source}

No funding was required.

\section{Ethical approval}

The protocol for this study was approved by the Biomedical Research Ethics Committee of the University of KwaZuluNatal (Ref No.: BE502/16).

\section{ORCID}

SM Chonco (iD https://orcid.org/0000-0002-9900-919X PN Mtetwa (iD https://orcid.org/0000-0002-2418-1454 M Naidoo (iD https://orcid.org/0000-0002-0628-8805

VG Naidoo (iD https://orcid.org/0000-0003-3774-9608 TE Madiba (iD https://orcid.org/0000-0002-0155-9143 


\section{REFERENCES}

1. Indiveri L, Berman R, Bhagowat $\mathrm{M}$, et al. A clinical audit of inflammatory bowel disease in a South African tertiary institution. S Afr Gastroenterol Rev. 2010;8:6-18. https://doi. org/10.4314/sagr.v8i3.63098.

2. Seifarth C, Kreis ME, Gröne J. Indications and specific surgical techniques in Crohn's disease. Visc Med. 2015;31:273-9. https://doi.org/10.1159/000438955.

3. Abdalla $\mathrm{M}$, Landerholm $\mathrm{K}$, Andersson $\mathrm{P}$, Andersson RE, Myrelid P. Risk of rectal cancer after colectomy for patients with ulcerative colitis: a national cohort study. Clin Gastroenterol Hepatol. 2017;15:1055-60. https://doi. org/10.1016/j.cgh.2016.11.036.

4. Ye Y, Pang Z, Chen W, Ju S, Zhou C. The epidemiology and risk factors of inflammatory bowel disease. Int J Clin Exp Med. 2015;8:22529-42.

5. Ng SC, Shi HY, Hamidi N, et al. Worldwide incidence and prevalence of inflammatory bowel disease in the $21 \mathrm{st}$ century: a systematic review of population-based studies. Lancet. 2017;390:2769-78. https://doi.org/10.1016/S01406736(17)32448-0

6. Molodecky NA, Soon IS, Rabi DM, et al. Increasing incidence and prevalence of the inflammatory bowel diseases with time, based on systematic review. Gastroenterology. 2012;142:4654.e42. https://doi.org/10.1053/j.gastro.2011.10.001.

7. Cosnes J, Gower-Rousseau C, Seksik P, Cortot A. Epidemiology and natural history of inflammatory bowel diseases. Gastroenterology. 2011;140:1785-94.e4. https://doi. org/10.1053/j.gastro.2011.01.055.

8. Su HJ, Chiu YT, Chiu CT, et al. Inflammatory bowel disease and its treatment in 2018: Global and Taiwanese status updates. J Formos Med Assoc. 2019;118:1083-92. https://doi. org/10.1016/j.jfma.2018.07.005.

9. Senbanjo IO, Oshikoya KA, Onyekwere CA, Abdulkareem FB, Njokanma OF. Ulcerative colitis in a Nigerian girl: a case report. BMC Res Notes. 2012;5:564-7. https://doi. org/10.1186/1756-0500-5-564.

10. Øresland T, Bemelman WA, Sampietro GM, et al. European evidence based consensus on surgery for ulcerative colitis. J Crohn's Colitis. 2014;9:4-25. https://doi.org/10.1016/j. crohns.2014.08.012.

11. Lin $\mathrm{CC}$, Wei $\mathrm{SC}$, Lin $\mathrm{BR}$, et al. A retrospective analysis of 20-year data of the surgical management of ulcerative colitis patients in Taiwan: a study of Taiwan Society of Inflammatory Bowel Disease. Intest Res. 2016;14:248. https://doi. org/10.5217/ir.2016.14.3.248.

12. Ross H, Steele SR, Varma M, et al. Practice parameters for the surgical treatment of ulcerative colitis. Dis Colon Rectum. 2014;57:5-22. https://doi.org/10.1097/ DCR.0000000000000030.

13. Muldoon R, Herline AJ. Crohn's Disease: Surgical Management. In: Steele SR, Hull TL, Read TE, et al, editors. The ASCRS Textbook of Colon and Rectal Surgery. Springer. 2016. p. 843-68. https://doi.org/10.1007/978-3-319-25970-3.

14. Watermeyer G, Epstein D, Adegoke O, et al. Epidemiology of inflammatory bowel disease in sub-Saharan Africa: a review of the current status. S Afr Med J. 2020;110:1006-9. https:// doi.org/10.7196/SAMJ.2020.v110i10.14489.

15. Hodges P, Kelly P. Inflammatory bowel disease in Africa: what is the current state of knowledge? Int Health. 2020;12:222-30. https://doi.org/10.1093/inthealth/ihaa005.

16. Basson A, Swart R, Jordaan E, Mazinu M, Watermeyer G. The association between race and Crohn's disease phenotype in the Western Cape population of South Africa, defined by the Montreal Classification System. PLoS One. 2014;9:e104859. https://doi.org/10.1371/journal.pone.0104859.

17. Mokhele NN, Thomson S, Watermeyer GA. Predictors of emergency colectomy in patients admitted with acute severe ulcerative colitis. S Afr J Surg. 2017;55:20-6.

18. Myer L, Ehrlich RI, Susser ES. Social epidemiology in South Africa. Epidemiol Rev. 2014;26:112-3.https://doi. org/10.1093/epirev/mxh004.

19. Satsangi J, Silverberg MS, Vermeire S, Colombel JF. The Montreal classification of inflammatory bowel disease: controversies, consensus, and implications. Gut. 2006;55:74953. https://doi.org/10.1136/gut.2005.082909.

20. Levine JS, Burakoff R. Extraintestinal manifestations of inflammatory bowel disease. Gastroenterol Hepatol. 2011;7:235.

21. Wei SC, Shieh MH, Chang MC, et al. Long-term followup of ulcerative colitis in Taiwan. J Chinese Med Assoc. 2012;75:151-5. https://doi.org/10.1016/j.jcma.2012.02.017.

22. De Alencar SS, Corrêa R, Bezerra C, et al. The surgical treatment of patients with ulcerative colitis from an university hospital at Natal, Brazil. J Coloproctology (Rio Janeiro). 2012;32:265-70. https://doi.org/10.1590/S2237 93632012000300010 .

23. Betteridge JD, Armbruster SP, Maydonovitch C, Veerappan GR. Inflammatory bowel disease prevalence by age, gender, race, and geographic location in the U.S. military health care population. Inflamm Bowel Dis. 2013;19:1421-7. https://doi. org/10.1097/MIB.0b013e318281334d.

24. Peng QH, Wang YF, He MQ, Zhang C, Tang Q. Clinical literature review of 1858 Crohn's disease cases requiring surgery in China. World J Gastroenterol. 2015;21:4735. https://doi.org/10.3748/wjg.v21.i15.4735.

25. Fazio VW, Kiran RP, Remzi FH, et al. Ileal pouch anal anastomosis: analysis of outcome and quality of life in 3707 patients. Ann Surg. 2013;257:679-85. https://doi.org/10.1097/ SLA.0b013e31827d99a2.

26. De Silva S, Ma C, Proulx MC, et al. Postoperative complications and mortality following colectomy for ulcerative colitis. Clin Gastroenterol Hepatol. 2011;9:972-80. https://doi.org/10.1016/j.cgh.2011.07.016.

27. Zhulina Y, Udumyan R, Tysk C, Montgomery S, Halfvarson J. The changing face of Crohn's disease: a population-based study of the natural history of Crohn's disease in Örebro, Sweden 1963-2005. Scand J Gastroenterol. 2016;51:304-13. https://doi.org/10.3109/00365521.2015.1093167.

28. Gecse K, Khanna R, Stoker J, et al. Fistulizing Crohn's disease: diagnosis and management. United Eur Gastroenterol J. 2013;1(3):206-13. https://doi. org/10.1177/2050640613487194.

29. Steele SR, Kumar R, Feingold DL, Rafferty JL, Buie WD. Practice parameters for the management of perianal abscess and fistula-in-ano. Dis Colon Rectum. 2011;54(12):1465-74. https://doi.org/10.1097/DCR.0b013e31823122b3.

30. Gionchetti P, Dignass A, Danese S, et al. 3rd European evidence-based consensus on the diagnosis and management of Crohn's disease 2016: Part 2: surgical management and special situations. J Crohn's Colitis. 2017;11:135-49. https:// doi.org/10.1093/ecco-jcc/jjw169.

31. Simillis C, Yamamoto T, Reese GE, et al. A meta-analysis comparing incidence of recurrence and indication for reoperation after surgery for perforating versus nonperforating Crohn's disease. Am J Gastroenterol. 2008;103(1):196-205. 
32. Jess T, Loftus EV Jr, Velayos FS, et al. Risk of intestinal cancer in inflammatory bowel disease: a population-based study from olmsted county, Minnesota. Gastroenterology. 2006;130(4):1039-46. https://doi.org/10.1053/j.gastro.2005.1 2.037 .

33. Beaugerie L, Itzkowitz SH. Cancers complicating inflammatory bowel disease. N Engl J Med. 2015;372:144152. https://doi.org/10.1056/NEJMra1403718.

34. Weiser TG, Gawande A. Excess surgical mortality: strategies for improving quality of care. In: Debas HT, Donkor P, Gawande A, Jamison DT, Kruk ME, Mock CN, editors. Essential surgery: disease control priorities. 3rd ed. (Volume 1). Washington (DC): The International Bank for Reconstruction and Development / The World Bank; 2015 Apr 2. Chapter 16.

35. Sica GS, Biancone L. Surgery for inflammatory bowel disease in the era of laparoscopy. World J Gastroenterol. 2013;19:2445-8. https://doi.org/10.3748/wjg.v19.i16.2445. 